\title{
Plant-mediated synthesis of silver nanoparticles using parsley (Petroselinum crispum) leaf extract: spectral analysis of the particles and antibacterial study
}

\author{
Kaushik Roy $\cdot$ C. K. Sarkar $\cdot$ C. K. Ghosh
}

Received: 22 November 2014 / Accepted: 17 December 2014 / Published online: 27 December 2014

(C) The Author(s) 2014. This article is published with open access at Springerlink.com

\begin{abstract}
Synthesis of nanomaterials may involve various routes including physical, chemical and biological approaches. Here, the biological green route was chosen to prepare silver nanoparticles from silver salts to avoid the requirement of costly instruments and involvement of hazardous chemicals as well. To make the process clean and green, leaf extract of parsley (Petroselinum crispum) was used to synthesize $\mathrm{Ag}$ nanoparticles at room temperature. The formation of Ag-nanoparticles was monitored by UV-Vis spectroscopy. The presence of silver in the sample and its crystalline nature were verified by X-ray diffraction (XRD) analysis. The size distribution profile and particle size in the suspension were manipulated from dynamic light scattering (DLS) pattern. The shape, size and morphology of the biogenic nanoparticles were studied using high resolution transmission electron microscope (TEM). Fourier transform infra-red spectroscopy was used to detect the biomolecules responsible for reduction of silver ions. These biogenic Ag-nanoparticles showed appreciable antibacterial efficacy against three bacteria-Klebsiella pneumoniae, Escherichia coli and Staphylococcus aureus.
\end{abstract}

Keywords Silver nanoparticles · Parsley (Petroselinum crispum) leaf extract · UV-Vis spectroscopy · XRD . TEM $\cdot$ Antibacterial activity

\section{K. Roy $(\bowtie) \cdot$ C. K. Sarkar}

Department of Electronics and Telecommunication Engineering, Jadavpur University, Kolkata 700032, India

e-mail: lordkaushikroy@gmail.com

K. Roy · C. K. Ghosh

School of Material Science and Nanotechnology, Jadavpur University, Kolkata 700032, India

\section{Introduction}

Research on advanced nanomaterials of noble metals like silver has gained a lot of interest among scientists during the past decades due to their unique properties that originate from high number of surface atoms and their versatile utilities and innovative applications in various engineering fields like catalysis (Santos et al. 2012), optical (Das et al. 2010) and antimicrobial activity (Soo-Hwan et al. 2011; Venkatesham et al. 2014; El-Nour et al. 2010), etc. Synthesis method of nanoparticles plays an important role in its technological advancement as it is the primary step to tune their physical, electronic, and optical properties of the synthesized nanoparticles by varying size, shape and surface chemistry (Wiley et al. 2007; Sharma et al. 2009; Naik et al. 2002). Conventional procedures such as chemical reduction (Szczepanowicz et al. 2010), microwave-aided method (Zhu et al. 2013) and photocatalytic reaction (Scaiano et al. 2009) involve a variety of toxic chemicals like surfactants, polymers, starch, citrates, hydrides, lipids, etc., for synthesis of stable and agglomeration-free $\mathrm{Ag}$ nanomaterials but the by-products of these procedures were found to be hazardous to animals and environment (Welton 1999; Vinod et al. 2011; Chen et al. 2005; Bakshi et al. 2008; Bakshi 2009; Esumi et al. 2000). Recently, biological methods using biological microorganism, plant extract, and enzymes have proved itself an easy, cost-effective and ecofriendly alternative synthesis route of metallic nanoparticle compared to conventional procedures (Li et al. 2007; Mittal et al. 2013; Tamulya et al. 2013). Among different biological routes developed so far, synthesis methods using either plant extract or fruit extract have several advantages over others as it does not require any cell culture and the process can easily be scaled up for large scale synthesis. Numerous reports have already been established to

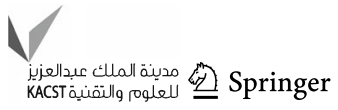


synthesize metal nanoparticles using plant extract of Aloe vera (Chandran et al. 2006), Phyllanthus emblica (Saini et al. 2013), Azadirachta indica (Saini et al. 2013; Lalitha et al. 2013), Rhinacanthus nasutus (Pasupuleti et al. 2013), Memecylon edule (Elavazhagan and Arunachalam 2011), Magnolia kobus (Lee et al. 2013), Cymbopogan citratus (Masurkar et al. 2011), Morinda tinctoria (Vanaja et al. 2014), Malus domestica (Roy et al. 2014), etc.

Here we have reported another approach for biological green synthesis of silver nanoparticles using parsley (Petroselinum crispum) leaf extract. Parsley (Petroselinum crispum) is a type of Mediterranean herb whose leaves are rich source of Vitamin $\mathrm{C}$ (ascorbic acid). The high content of ascorbic acid in parsley leaves can play vital role as it acts as a strong reducing agent in this reaction. It reduced the silver cations present in the silver nitrate solution during interaction (Rodríguez-León et al. 2013) and caused the formation of $\mathrm{Ag}$ nanoparticles at room temperature. Later, antibacterial efficacy of these biosynthesized Agnanoparticles was tested against three bacteria-Klebsiella pneumoniae, Escherichia coli and Staphylococcus aureus.

\section{Materials and methods}

\section{Materials}

To prepare parsley (Petroselinum crispum) leaf extract, fresh parsley leaves (Fig. 1) were collected from local market. Silver nitrate used for this research was a product of Merck India Limited. The cultures of bacterial strainsKlebsiella pneumoniae, Escherichia coli and Staphylococcus aureus were procured from the National Chemical Laboratory, Pune, India. Nutrient agar media and Agar powder required for antibacterial study were purchased from Himedia, India.

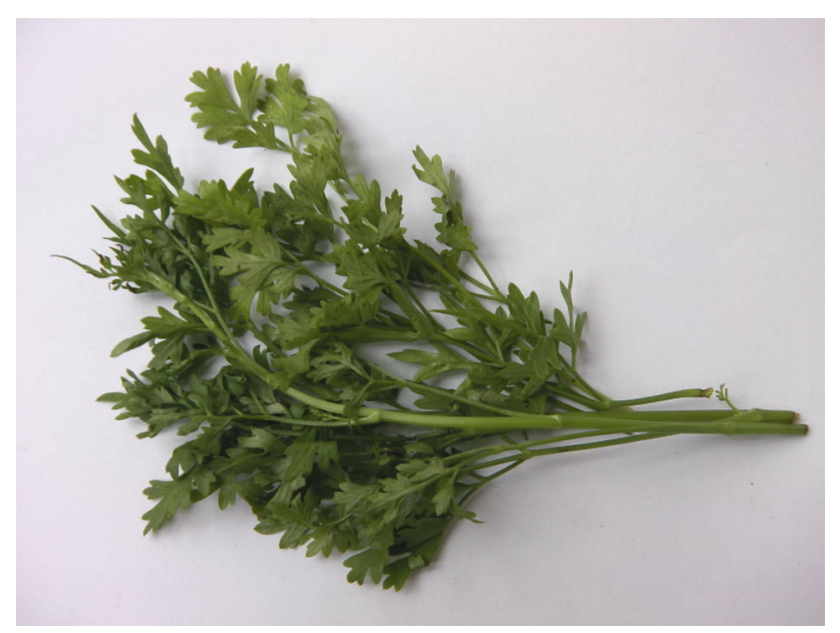

Fig. 1 Fresh parsley (Petroselinum crispum) leaves
Methods

Preparation of silver nanoparticles

To prepare the leaf extract of parsley (Petroselinum crispum), fresh parsley leaves (weight $50 \mathrm{~g}$ ) were cleaned, cut into small pieces and boiled in $100 \mathrm{ml}$ deionized water for 15 min. After cooling, the mixture was filtered to obtain clear and pure leaf extract of parsley (Petroselinum crispum). $0.34 \mathrm{~g}$ silver nitrate was dissolved in $100 \mathrm{ml}$ deionized water for preparing $20 \mathrm{mM}$ stock solution of $\mathrm{AgNO}_{3}$. For reducing $\mathrm{Ag}^{+}$ions present in silver nitrate solution, equal amount of parsley (Petroselinum crispum) leaf extract was added drop wise so that the final concentration of the solution remained $10 \mathrm{mM}$. The color of the mixture changed after $24 \mathrm{~h}$ and the silver ion reduction was monitored by UV-Vis spectroscopy of the solution. To obtain pure nanoparticles from the mixture, the solution was centrifuged at $10,000 \mathrm{rpm}$ for $30 \mathrm{~min}$. The precipitate was re-dispersed in $10 \mathrm{ml}$ deionized water and centrifuged at 5,000 rpm again for $15 \mathrm{~min}$ for removing unexpected biomass residue. Decanting the soup, the pellet of $\mathrm{Ag}$ nanoparticles was collected carefully and dried inside a desiccator overnight to obtain the dry powder of $\mathrm{Ag}$ nanoparticles. The dried powder of silver nanoparticles was used for further analysis.

\section{Characterization of silver nanoparticles}

The formation of $\mathrm{Ag}$ nanoparticles was investigated by scanning the original mixture under Perkin Elmer UV-Vis spectroscope (Lambda-35) in the wavelength range between 300 and $700 \mathrm{~nm}$ after $24 \mathrm{~h}$ of incubation period. X-ray diffractometer (Ultima-III, Rigaku, Japan, $\lambda=1.54 \AA$ ) was used to identify proper phase and crystallinity of the synthesized Ag nanoparticles. Dynamic light scattering technique was employed to analyze the size distribution profile of the nanoparticles present in the solution. Transmission electron microscopy (TEM, $200 \mathrm{kV}$, JEOL-2010) was used to know the shape, size and internal morphology of the synthesized nanoparticles. A couple of drops of Ag-nanoparticle suspension (concentration $50 \mu \mathrm{g} / \mathrm{ml}$ ) was placed on carbon coated copper grid and dried inside a vacuum dryer. The copper grid was then scanned by TEM to examine the nanoparticles. To prepare the sample for DLS analysis, the dried powder of Ag nanoparticles was suspended in deionized water maintaining a certain concentration (around $50 \mu \mathrm{g} / \mathrm{ml}$ ). Malvern DLS equipment was used to perform the dynamic light scattering analysis of these biosynthesized Ag nanoparticles. Fourier transform infrared spectroscopy (FTIR, IR-Prestige 21, Shimadzu) was engaged to detect organic compounds present in the leaf extract and responsible for reducing silver ions to form $\mathrm{Ag}$ nanoparticles. 


\section{Study of antibacterial activity of Ag nanoparticles}

The antibacterial activity of the biologically synthesized $\mathrm{Ag}$ nanoparticles was studied against three bacteria using conventional disc diffusion procedure. All cultures were maintained carefully on nutrient agar medium in favorable ambience. Parsley (Petroselinum crispum) leaf extract was taken as a control for comparative study. The leaf extract of parsley (Petroselinum crispum) and suspension of $\mathrm{Ag}$ nanoparticles were applied individually in two different wells created on each disc seeded with bacteria. The bacteria were then allowed to grow overnight inside an incubator at $37{ }^{\circ} \mathrm{C}$ (in darkness). The antibacterial activity of the sample was assessed by observing and measuring the inhibition zone formed around the cups after $24 \mathrm{~h}$.

\section{Results and discussions}

\section{$\mathrm{UV}-\mathrm{V}$ is spectroscopy}

The color of the solution changed distinctively from light yellow to dark brown after $24 \mathrm{~h}$ of addition of extract (shown in Fig. 2) suggesting the formation of Ag nanoparticles (Moores and Goettmann 2006). The Ag nanoparticle formation by reducing $\mathrm{Ag}^{+}$ions during exposure of parsley (Petroselinum crispum) leaf extract was investigated by UV-Vis spectroscopy. The UV-Vis absorption spectra of the mixtures containing different concentrations of $\mathrm{AgNO}_{3}(5,10,20,25 \mathrm{mM})$ were obtained after $24 \mathrm{~h}$ period of observation and are shown in Fig. 3a. The peak of absorbance, found near the wavelength $460 \mathrm{~nm}$, can be attributed to the plasmonic peak of $\mathrm{Ag}$ nanoparticles, formed in the solution. There is no shift in the peak

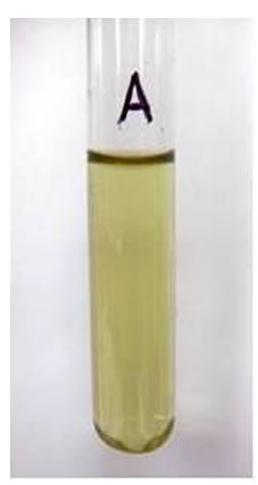

\section{A. Color of the mixture immediately after mixing}
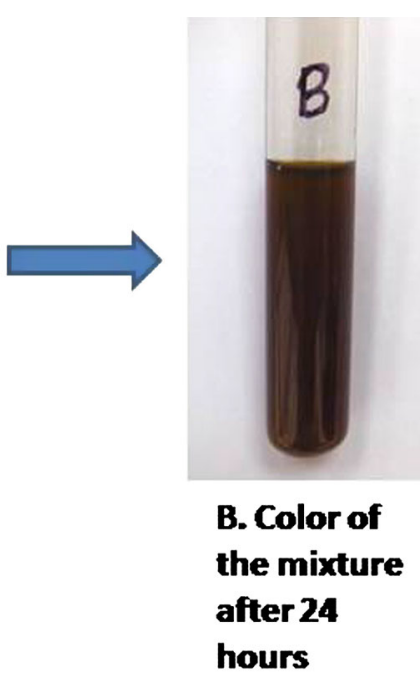

Fig. 2 Color change indicates formation of silver nanoparticles
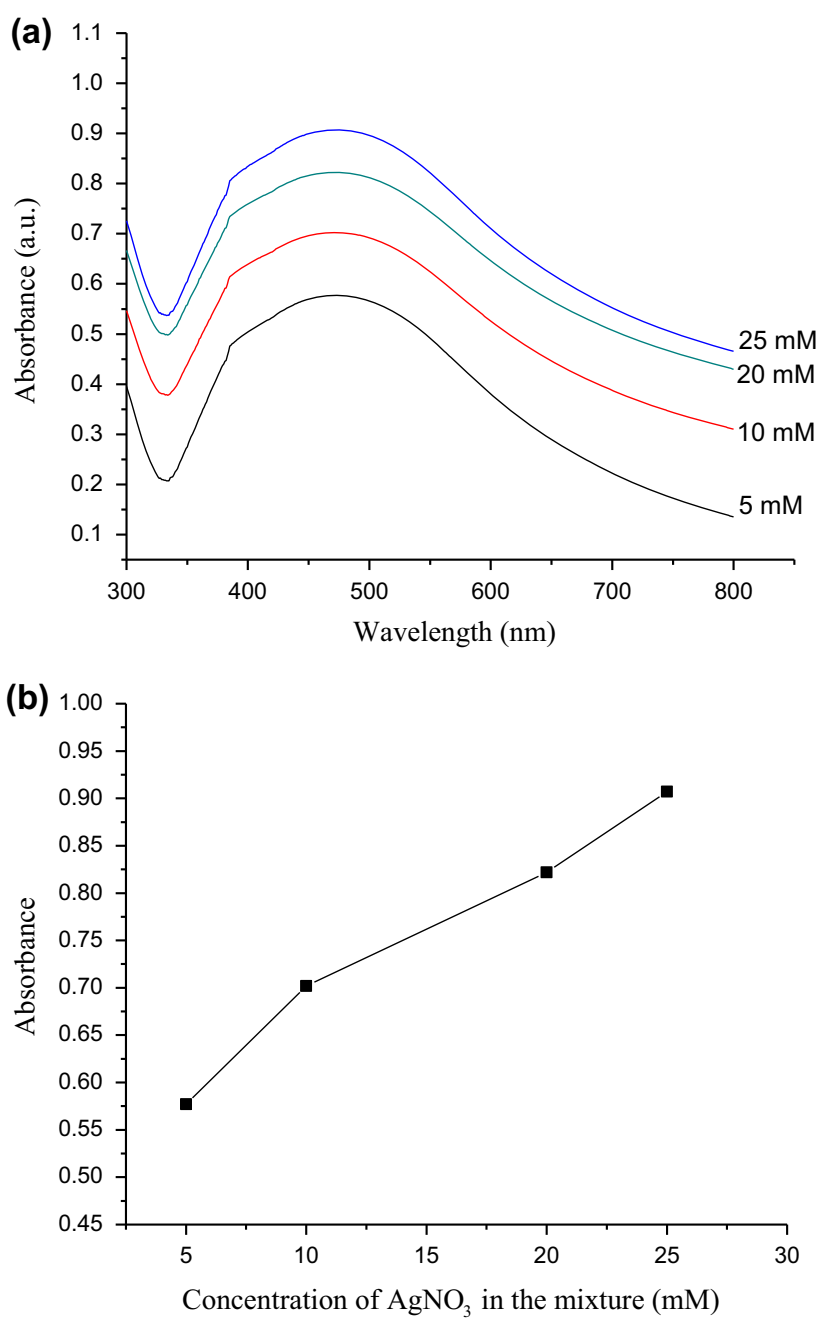

Fig. 3 a UV-Vis absorption spectra of biogenic Ag-nanoparticles. b Variation of absorbance maxima with $\mathrm{AgNO}_{3}$ concentration

position as concentration increases, hence, it can be concluded that the size of the formed nanoparticles varies with concentration. Figure $3 \mathrm{~b}$ indicates the variation of maximum absorbance with the concentration of silver nitrate in the mixture. It may be observed that the variation of maximum absorbance with concentration is almost linear indicating the linear increase in the rate of formation of $\mathrm{Ag}$ nanoparticles with the concentration of $\mathrm{AgNO}_{3}$ in the mixture.

\section{XRD analysis}

The XRD result confirmed the presence of silver in the sample again. The XRD pattern of dry powder of $\mathrm{Ag}$ nanoparticles shows clear diffraction line at low angles i.e., $10-80^{\circ}$ (shown in Fig. 4). The XRD graph shows peaks of silver at $2 \theta=27.86^{\circ}, 32.14^{\circ}, 37.96^{\circ}, 46.06^{\circ}, 55.02^{\circ}$ and $57.03^{\circ}$ that can be attributed to the (220), (122), (111), 


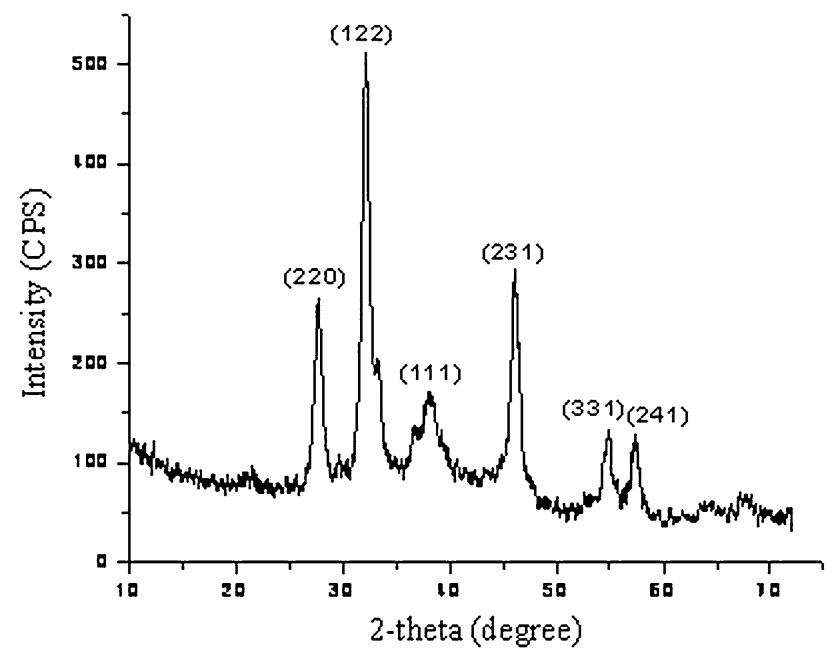

Fig. 4 XRD pattern of the biosynthesized silver nanoparticles

(231), (331) and (241) facets of Ag. These entire diffraction peaks match very well not only with their respective peak positions but also with their relative peak intensities (correlated to JCPDS card: File no. 4-783). Presence of no peak other than the characteristic peaks of $\mathrm{Ag}$ suggests high level of purity of these biosynthesized silver nanoparticles.

Dynamic light scattering analysis

Figure 5 shows the DLS pattern of the suspension of $\mathrm{Ag}$ nanoparticles synthesized using parsley (Petroselinum crispum) leaf extract. The size distribution profile indicates that the size (diameter) of these silver nanoparticles varies between 3 and $50 \mathrm{~nm}$. The distribution is very much asymmetric in nature. High intensity of the distribution at lower range of particle size indicates that the most of the synthesized particles are in lower range of particle size. Maximum intensity of the size distribution pattern is found to be close to $25 \mathrm{~nm}$, i.e., most of the particles lie in the range of $25-30 \mathrm{~nm}$.

\section{TEM analysis}

Transmission electron microscopy was used to investigate the microstructure and crystallinity of the silver nanoparticles synthesized using leaf extract of parsley (Petroselinum crispum). It is clear from high resolution TEM image (Fig. 6) that the as prepared Ag nanoparticles possess spherical shape with an average diameter nearly 30-32 nm. Particle size as obtained from TEM closely matches with that obtained from DLS. The spacing between the planes is measured to be nearly $0.28 \mathrm{~nm}$ that may be assigned to the (122) planes of the biosynthesized Ag nanoparticles.

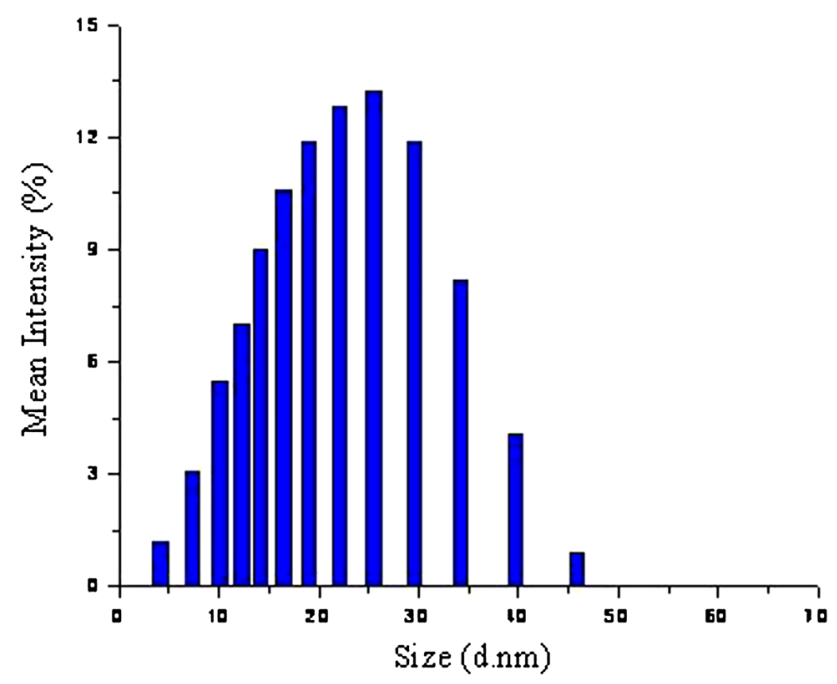

Fig. 5 DLS pattern of biogenic silver nanoparticles

\section{FTIR spectroscopy}

To identify the molecules responsible for reduction and stabilization of Ag nanoparticles, Fourier transform infrared spectroscopy was employed. Figure 7 depicts the FTIR spectrum of the parsley (Petroselinum crispum) leaf extract-mediated silver nanoparticles in absorbance mode. The spectrum reveals eight distinct bands throughout the entire range of observation. The bands at 1,656 and $2,931 \mathrm{~cm}^{-1}$ denote the $\mathrm{C}=\mathrm{O}$ stretching of tertiary amides and C-H stretching of aldehydes, respectively (Rimal Isaac et al. 2013). The bands at 1,247 and $3,284 \mathrm{~cm}^{-1}$ correspond to the $\mathrm{C}-\mathrm{O}$ stretching and $\mathrm{O}-\mathrm{H}$ stretching of benzene ring compounds (like ascorbic acid), respectively (Rimal Isaac et al. 2013). A band at $1,080 \mathrm{~cm}^{-1}$ indicates the $\mathrm{C}-\mathrm{N}$ stretching vibration of amines whereas a band at $1,564 \mathrm{~cm}^{-1}$ denotes the bending of $\mathrm{C}-\mathrm{H}$ bonds present in hydrocarbons (Sathyavathi et al. 2010). The remaining two bands at 972 and $1,392 \mathrm{~cm}^{-1}$ can be assigned to the $\mathrm{C}-\mathrm{H}$ bending of alkenes and alkanes, respectively (Smith 1999). From the FTIR study of biogenic silver nanoparticles, it may be concluded that the ascorbic acid along with alcohol and aldehydes could play the role of reducing and capping agents resulting in the formation and stabilization of $\mathrm{Ag}$ nanoparticles in the medium.

\section{Analysis of antibacterial activity}

Antibacterial activity of these biosynthesized Ag nanoparticles was tested against three bacteria: two gram negative bacteria-Klebsiella pneumoniae and Escherichia coli and one gram positive bacterium-Staphylococcus aureus. After applying the suspension of Ag-nanoparticles in different wells, the bacterial strains were incubated 
Fig. 6 i-iii HRTEM images of biosynthesized silver nanoparticles

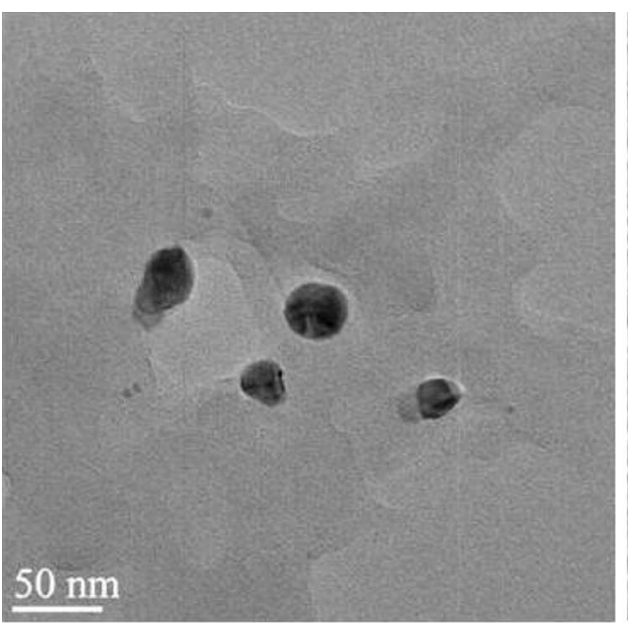

(i)

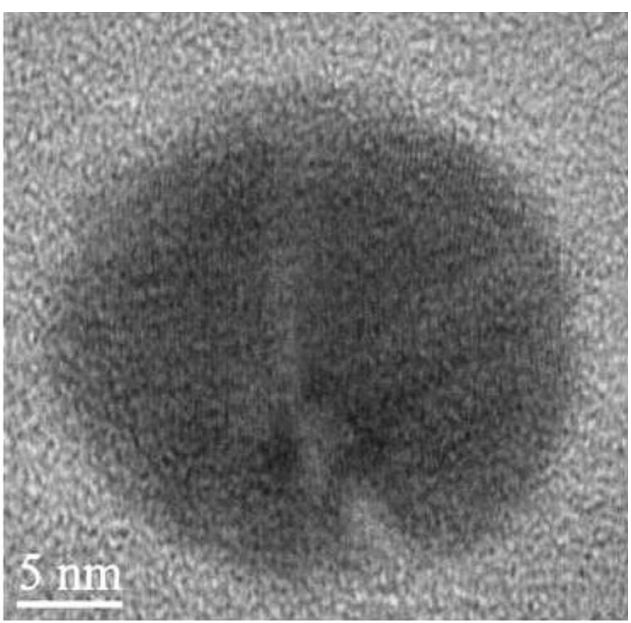

(ii)

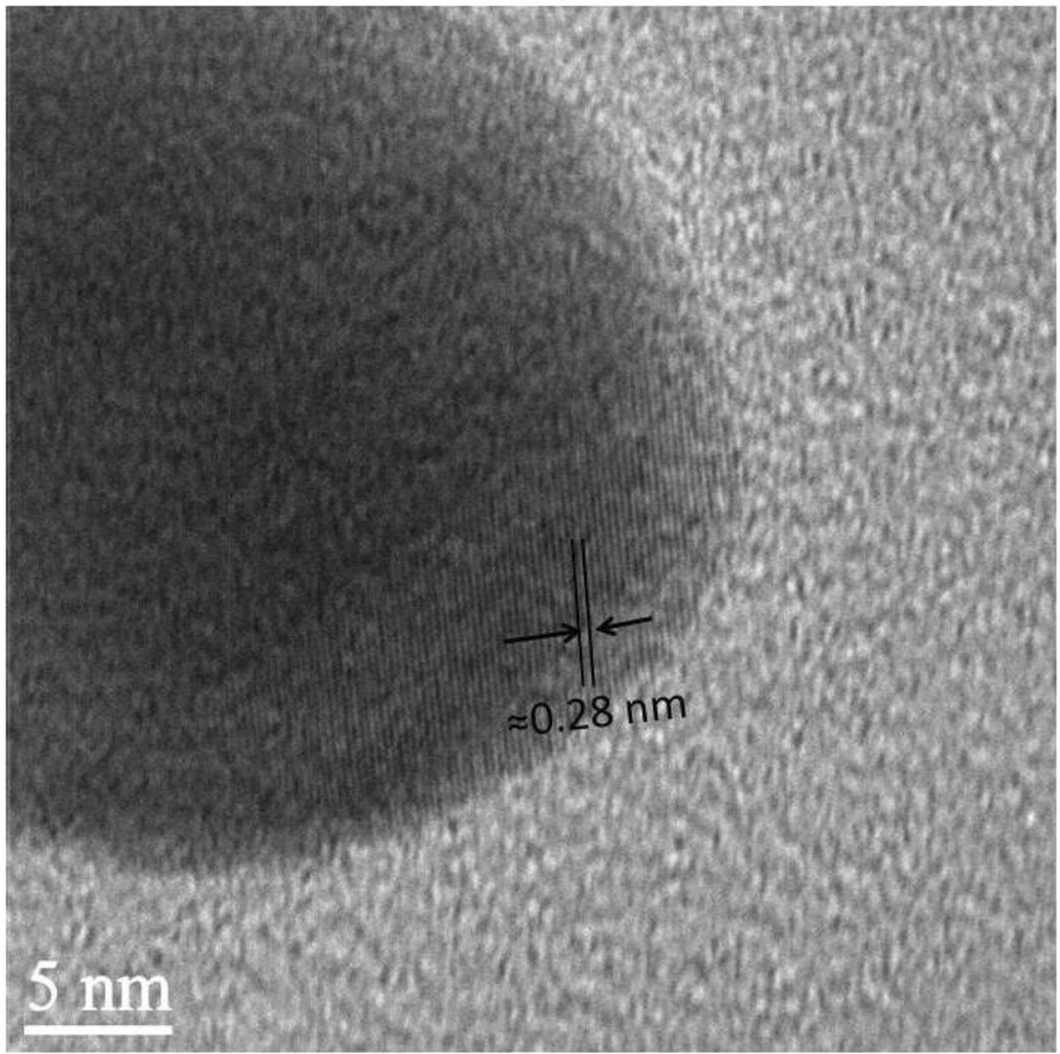

(iii)

overnight at $37^{\circ} \mathrm{C}$ in darkness. After $24 \mathrm{~h}$, clear inhibition zones were observed around the wells where Ag-nanoparticle suspension with two different concentrations (25 and $50 \mu \mathrm{g} / \mathrm{ml}$ ) was used. But the control, i.e., pure leaf extract of parsley (Petroselinum crispum) could not prevent the growth of these bacteria resulting in the absence of inhibition zone around the cups where it was applied. Table 1 depicts that these biosynthesized Ag nanoparticles inhibited the growth of all these three bacteria to various levels. We report the maximum activity against
Escherichia coli $(14.15 \mathrm{~mm})$. The suspension of $\mathrm{Ag}$ nanoparticles curbed the growth of other two organismsKlebsiella pneumoniae $(13.35 \mathrm{~mm})$ and Staphylococcus aureus $(12.50 \mathrm{~mm})$ as shown in Table 1.

The diameter of inhibition zone is higher in case of the gram negative bacteria-E. coli and Klebsiella pneumoniae as compared to the inhibition zone formed against Staphylococcus aureus which is gram positive bacteria. This is perhaps because the cell wall of gram positive bacteria comprises of multi-layer peptidoglycan whereas the cell wall 


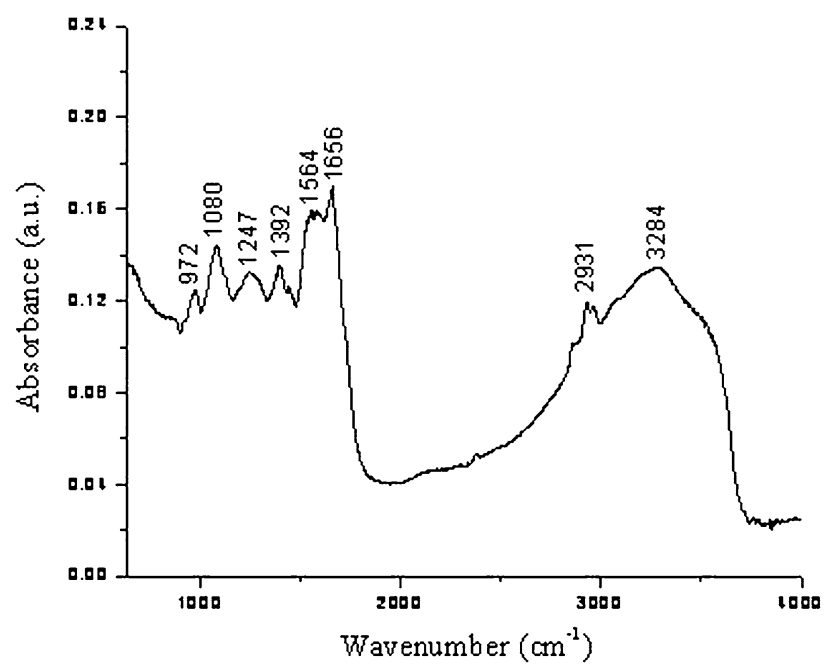

Fig. 7 FTIR spectrum of the biosynthesized Ag nanoparticles

Table 1 Result of antibacterial Study

\begin{tabular}{cll}
\hline Bacteria tested & $\begin{array}{l}\text { Concentration of Ag } \\
\text { nanoparticles in } \\
\text { suspension }\end{array}$ & $\begin{array}{l}\text { Diameter of Inhibition } \\
\text { Zone (mean of triplicates) } \\
(\mathrm{mm})\end{array}$ \\
\hline $\begin{array}{c}\text { Klebsiella } \\
\text { pneumoniae }\end{array}$ & Control & 0 \\
& $25 \mu \mathrm{g} / \mathrm{ml}$ & 6.55 \\
Escherichia coli & Control & 13.35 \\
& $25 \mu \mathrm{g} / \mathrm{ml}$ & 0 \\
Staphylococcus & Control & 6.95 \\
aureus & $25 \mu \mathrm{g} / \mathrm{ml}$ & 14.15 \\
& $50 \mu \mathrm{g} / \mathrm{ml}$ & 0 \\
\hline
\end{tabular}

of gram negative bacteria is composed of single or double layer of peptidoglycan (Shrivastava et al. 2007; Prakasha et al. 2013). Hence, the penetration of Ag nanoparticles into the bacterial cell was easier in case of gram negative bacteria than gram positive. When Ag nanoparticles come in contact with the bacterial cells, the cellular membrane ruptures leading to the gradual increase in permeability of cell membrane (Dibrov et al. 2002). The cellular transport is degraded due to increased permeability of the plasma membrane resulting in the death of the bacterial cell, as reported by Sondi et al. (Sondi and Salopek-Sondi 2004).

\section{Conclusion}

This study reported that the Ag nanoparticles can be synthesized by an easy, convenient and eco-friendly method using the leaf extract of parsley (Petroselinum crispum). The leaf extract contains reducing agents (mainly ascorbic acid) that reduced silver ions and formed Ag nanoparticles at room temperature. The metallic nanoparticles were almost spherical in shape with an average particle size around $30 \mathrm{~nm}$. The result of antibacterial study showed that these biologically synthesized Ag-nanoparticles have the antibacterial property to prevent the growth of a few common bacteria as well. These biosynthesized silver nanoparticles can be explored as a viable option for reducing infective potential of the tested bacterial species.

Acknowledgments One of the authors (Kaushik Roy) thankfully acknowledges Council of Scientific and Industrial Research for Senior Research Fellowship.

Open Access This article is distributed under the terms of the Creative Commons Attribution License which permits any use, distribution, and reproduction in any medium, provided the original author(s) and the source are credited.

\section{References}

Bakshi MS (2009) A simple method of Superlattics formation: step by step evaluation of crystal growth of gold nanoparticles through seed-growth method. Langmuir 25:12697-12705

Bakshi MS, Possmayer F, Petersen NO (2008) Aqueous phase room temperature synthesis of gold nanoribbons: soft template effect of a Gemini surfactant. J Phys Chem C 112:8259-8265

Chandran SP, Chaudhary M, Pasricha R, Ahmad A, Sastry M (2006) Synthesis of gold nanotriangles and silver nanoparticles using Aloe vera plant extract. Biotechnol Progress 22(2):577-583

Chen J, Herricks T, Xia Y (2005) Polyol synthesis of platinum nanostructures: control of morphology through the manipulation of reduction kinetics. Angewandte Chemie Int Edit 44(17):2589-2592

Das R, Nath SS, Chakdar D, Gope G, Bhattacharjee R (2010) Synthesis of silver nanoparticles and their optical properties. J Exp Nanosci 5(4):357-362

Dibrov P, Dzioba J, Gosink KK, Häse CC (2002) Chemiosmotic mechanism of antimicrobial activity of $\mathrm{ag}^{+}$in vibrio cholerae. Antimicrob Agent Chemo 46(8):2668-2670

Elavazhagan T, Arunachalam KD (2011) Memecylon edule leaf extract mediated green synthesis of silver and gold nanoparticles. Int J Nanomd 6:1265-1278

El-Nour KMMA, Eftaiha A, Al-Warthan A, Ammar RAA (2010) Synthesis and application of silver nanoparticles. Arab J Chem 3(3): 135-140

Esumi K, Hosoya T, Suzuki A, Torigoe K (2000) Formation of gold and silver nanoparticles in aqueous solution of sugar-persubstituted poly (amidoamine) dendrimers. J Colloid Interf Sci 226:346-352

Lalitha A, Subbaiya R, Ponmurugan P (2013) Green synthesis of silver nanoparticles from leaf extract Azhadirachta indica and to study its anti-bacterial and antioxidant property. Int J Cur Micro Appl Sci 2(6):228-235

Lee H, Song JY, Kim BS (2013) Biological synthesis of copper nanoparticles using Magnolia kobus leaf extract and their antibacterial activity. J Chem Tech Biotechnol 88(11):1971-1977

Li S, Shen Y, Xie A, Yu X, Qiu L, Zhang L, Zhang Q (2007) Green synthesis of silver nanoparticles using Capsicum annum $L$. Extract Green Chem 9:852-858

Masurkar SA, Chaudhari PR, Shidore VB, Kamble SP (2011) Rapid biosynthesis of silver nanoparticles using Cymbopogan citratus 
(lemongrass) and its antimicrobial activity. Nano-Micro Lett 3(3):189-194

Mittal AK, Chisti Y, Banerjee UC (2013) Synthesis of metallic nanoparticles using plant extracts. Biotechnol Adv 31(2):346-356

Moores A, Goettmann F (2006) The plasmon band in noble metal nanoparticles: an introduction to theory and applications. New J Chem 30:1121-1132

Naik RR, Stringer SJ, Agarwal G, Jones SE, Stone MO (2002) Biomimetic synthesis and patterning of silver nanoparticles. Nat Mater 1:169-172

Pasupuleti VR, Prasad TNVKV, Shiekh RA, Balam SK, Narasimhulu G, Reddy CS, Rahman IA, Gan SH (2013) Biogenic silver nanoparticles using Rhinacanthus nasutus leaf extract: synthesis, spectral analysis, and antimicrobial studies. Int $\mathrm{J}$ Nanomd 8:3355-3364

Prakasha P, Gnanaprakasama P, Emmanuela R, Arokiyarajb S, Saravanan M (2013) Green synthesis of silver nanoparticles from leaf extract of Mimusops elengi Linn. for enhanced antibacterial activity against multi drug resistant clinical isolates. Colloid Surf B: Biointerfaces 108:255-259

Rimal IRS, Sakthivel G, Murthy C (2013) Green synthesis of gold and silver nanoparticles using Averrhoa bilimbi fruit extract. J Nanotech Article ID 906592:6 pages, doi: 10.1155/2013/ 906592

Rodríguez-León E, Iñiguez-Palomares R, Navarro RE, HerreraUrbina R, Tánori J, Iñiguez-Palomares C, Maldonado A (2013) Synthesis of silver nanoparticles using reducing agents obtained from natural sources (Rumex hymenosepalus extracts). Nanoscale Res Lett 8:318-326

Roy K, Sarkar CK, Ghosh CK (2014) Green synthesis of silver nanoparticles using fruit extract of Malus domestica and study of its antimicrobial activity. Dig J Nanomat Bios 9(3):1137-1147

Saini J, Kashyap D, Batra B, Kumar S, Kumar R, Malik DK (2013) Microbial biotechnology Green synthesis of silver nanoparticles by using neem (Azadirachta indica) and amla (Phyllanthus emblica) leaf extract. Ind J Appl Res 3(5):209-210

Santos KO, Elias WC, Signori AM, Giacomelli FC, Yang H, Domingos JB (2012) Synthesis and catalytic properties of silver nanoparticle-linear polyethylene imine colloidal systems. J Phys Chem C 116(7):4594-4604

Sathyavathi R, Krishna MB, Rao SV, Saritha R, Rao DN (2010) Biosynthesis of silver nanoparticles using Coriandrum sativum leaf extract and their application in nonlinear optics. Adv Sci Lett 3(2):138-143

Scaiano JC, Billone P, Gonzalez CM, Maretti L, Marin ML, McGilvray KL, Yuan N (2009) Photochemical routes to silver and gold nanoparticles. Pure Appl Chem 81(4):635-647
Sharma VK, Yngard RA, Lin Y (2009) Silver nanoparticles: green synthesis and their antimicrobial activities. Adv Colloid Interf Sci 145:83-96

Shrivastava S, Bera T, Roy A, Singh G, Ramachandrarao P, Dash D (2007) Characterization of enhanced antibacterial effects of novel silver nanoparticles. Nanotech Article ID 225103:9 pages, doi: $10.1088 / 0957-4484 / 18 / 22 / 225103$

Smith BC (1999) Infrared spectral interpretation: a systematic approach. CRC Press, Florida Chapter 2

Sondi I, Salopek-Sondi B (2004) Silver nanoparticles as antimicrobial agent: a case study on E. coli as a model for Gram-negative bacteria. J Colloid Interf Sci 275:177-182

Soo-Hwan K, Lee H, Ryu D, Choi S, Lee D (2011) Antibacterial activity of Silver nanoparticles against Staphylococcus aureus and Escherichia coli. Kor J Micro Biotech 39(1):77-85

Szczepanowicz K, Stefanska J, Socha RO, Warszynski P (2010) Preparation of silver nanoparticles via chemical reduction and their antimicrobial activity. Physicochem Probl Miner Process 45:85-98

Tamulya C, Hazarika M, Borah SC, Das MR, Boruah MP (2013) In situ biosynthesis of $\mathrm{Ag}$, $\mathrm{Au}$ and bimetallic nanoparticles using Piper pedicellatum C.DC: green chemistry approach. Colloid Surf B Biointerfaces 102:627-634

Vanaja M, Paulkumar K, Baburaja M, Rajeshkumar S, Gnanajobitha G, Malarkodi C, Sivakavinesan M, Annadurai G (2014) Degradation of methylene blue using biologically synthesized silver nanoparticles. Bioinorg Chem Application Article Id 742346: 8 pages, doi: 10.1155/2014/742346

Venkatesham M, Ayodhya D, Madhusudhan A, Babu NV, Veerabhadram G (2014) A novel green one-step synthesis of silver nanoparticles using chitosan: catalytic activity and antimicrobial studies. Appl Nanosci 4(1):113-119

Vinod VTP, Saravanan P, Sreedhar V, Keerthi Devi D, Sashidhar RB (2011) A facile synthesis and characterization of Ag, Au and Pt nanoparticles using a natural hydrocolloid gum kondagogu (Cochlospermum gossypium). Colloid Surf B Biointerfaces 83(2):291-298

Welton T (1999) Room-temperature ionic liquids. Solvents for synthesis and catalysis. Chem Rev 99:2071-2083

Wiley B, Sun Y, Xia Y (2007) Synthesis of silver nanostructures with controlled shapes and properties. Account Chem Res 40:1067-1076

Zhu J, Shi J, Pan Y, Liu X, Zhou L (2013) Synthesis of uniform silver nanoparticles by a microwave method in polyethylene glycol with the assistant of polyvinylpyrrolidone. Wuhan Univ J Nat Sci 18(6):530-534 